\title{
Heme Deficiency in Alzheimer's Disease: A Possible Connection to Porphyria
}

\author{
Barney E. Dwyer, ${ }^{1,2}$ Meghan L. Stone, ${ }^{1}$ Xiongwei Zhu, ${ }^{3}$ George Perry, ${ }^{3}$ and Mark A. Smith ${ }^{3}$ \\ ${ }^{1}$ Research Service (151), VA Medical \& Regional Office Center, White River Junction, VT 05009, USA \\ ${ }^{2}$ Department of Medicine (Neurology), Dartmouth Medical School, Hanover, NH 03755, USA \\ ${ }^{3}$ Institute of Pathology, Case Western Reserve University, Cleveland, OH 44106, USA
}

Received 1 December 2005; Revised 30 March 2006; Accepted 5 April 2006

\begin{abstract}
Mechanisms that cause Alzheimer's disease $(\mathrm{AD})$, an invariably fatal neurodegenerative disease, are unknown. Important recent data indicate that neuronal heme deficiency may contribute to AD pathogenesis. If true, factors that contribute to the intracellular heme deficiency could potentially alter the course of $\mathrm{AD}$. The porphyrias are metabolic disorders characterized by enzyme deficiencies in the heme biosynthetic pathway. We hypothesize that AD may differ significantly in individuals possessing the genetic trait for an acute hepatic porphyria. We elaborate on this hypothesis and briefly review the characteristics of the acute hepatic porphyrias that may be relevant to $\mathrm{AD}$. We note the proximity of genes encoding enzymes of the heme biosynthesis pathway to genetic loci linked to sporadic, late-onset $\mathrm{AD}$. In addition, we suggest that identification of individuals carrying the genetic trait for acute porphyria may provide a unique resource for investigating $\mathrm{AD}$ pathogenesis and inform treatment and management decisions.
\end{abstract}

Copyright (C) 2006 Barney E. Dwyer et al. This is an open access article distributed under the Creative Commons Attribution License, which permits unrestricted use, distribution, and reproduction in any medium, provided the original work is properly cited.

\section{INTRODUCTION}

$\mathrm{AD}$ is a progressive and invariably fatal neurodegenerative disease and the leading cause of senile dementia [1]. Synaptic and neuronal loss best correlates with cognitive decline [2]. Metabolic imbalance in diseased neurons may contribute to neuropsychiatric symptoms that include delusions and hallucinations, anxiety, mood disorder, and sleep disturbance that are common in $\mathrm{AD}$ [3]. Mechanisms that cause $\mathrm{AD}$ are unknown. Recently we proposed a hypothesis that explains why elevated plasma homocysteine is a risk factor for $\mathrm{AD}$ $[4,5]$. Implicit in that hypothesis is development of neuronal heme deficiency, and evidence of heme deficiency in $\mathrm{AD}$ brains has been reported [6]. Here, we extend this theme by considering the possible impact of porphyria on $\mathrm{AD}$. The porphyrias are metabolic disorders characterized by enzyme deficiencies in the heme biosynthesis pathway. We propose that an understanding of porphyria may provide novel insights into $\mathrm{AD}$ pathogenesis.

\section{GENERAL CONSIDERATIONS}

Molecular and biochemical aspects of the porphyrias and their diagnosis and treatment are the subject of several excellent reviews [7-13]. Eight enzymes are required for de novo heme biosynthesis. With the exception of 5-aminolevulinic acid synthase [ALAS, EC 2.3.1.37], the initial and rate-limiting enzyme of the heme biosynthesis pathway, deficiency in one of the other seven enzymes is associated with a specific form of inherited porphyria [10]. Four of the hepatic porphyrias, so-called because liver is the major site of expression of the enzymatic defect in heme biosynthesis, are designated "acute" porphyrias because clinical expression of the disease is associated with an acute neurologic syndrome (the acute attack or porphyric crisis) $[8,11]$. These are the extremely rare Doss porphyria (deficiency of ALA dehydratase, EC 4.2.1.24), acute intermittent porphyria (deficiency of porphobilinogen deaminase, EC 4.3.1.8), hereditary coproporphyria (deficiency of coproporphyrinogen oxidase, EC 1.3.3.3), and variegate porphyria (deficiency of protoporphyrinogen oxidase, EC 1.3.3.4). Acute intermittent porphyria is generally the most common form of acute hepatic porphyria encountered. Significantly, enzyme deficiencies are present in other organs, including the brain, and the enzyme deficiency is life-long.

Acute neurologic syndrome associated with clinical attacks of acute hepatic porphyria can include both neuropsychiatric symptoms and neurodegenerative change $[8,11,12]$. Neuropsychiatric symptoms that include anxiety, insomnia, confusion, hallucinations, agitation, and paranoia (so-called 
porphyric encephalopathy-8) underscore CNS involvement. Autonomic neuropathy may underlie severe abdominal pain and cardiovascular symptoms. In severe cases, a peripheral neuropathy resembling Guillain-Barre syndrome can develop $[8,11]$. Clinical attacks of acute porphyria can be induced in latent individuals by a variety of environmental factors including many common medications, nutritional factors, restricted carbohydrate and calorie intake, smoking, and hormones such as progesterone; lists of safe and unsafe drugs are available $[9,11,12]$. A common mechanism of inducing agents is believed to be greatly increased hepatic heme demand. Thus, biosynthesis of cytochrome P450 enzymes that utilize heme as a prosthetic group can be induced as much as 40-50-fold in liver by drugs such as barbiturates [11]. Increased heme demand results in the induction of ALAS and increased synthesis of the heme precursor, 5-aminolevulinic acid [ALA]. In individuals who have inherited a partial deficiency in one of the enzymes of the heme biosynthesis pathway, that enzyme and not ALAS is the rate-limiting step in heme biosynthesis. Then, ALA and other heme precursors can accumulate. Moreover, heme biosynthesis is insufficient to meet demand and heme deficiency is unresolved. Acute attacks are treated with infusions of glucose and hemin $[9,12]$. Hemin restores the regulatory heme pool. This suppresses hepatic ALAS induction and the overproduction of ALA and other heme precursors. Glucose infusion may also suppress ALAS but by a different mechanism. Fasting, which can induce the acute attack, appears to activate transcriptional coactivator PGC- $1 \alpha$ (via a cAMP/CREB pathway) and PGC- $1 \alpha$ greatly increases hepatic ALAS expression by activating transcription factors NRF-1 and FOXO1 $[14,15]$. In addition, ALAS may respond directly to cAMP $[14,15]$. Glucose appears to antagonize both pathways. Abdominal pain and psychotic symptoms resolve quickly upon timely treatment of the acute attack but peripheral neuropathy can require months to resolve and recovery is often incomplete [11].

The pathogenesis of nervous system dysfunction in the acute attack remains unclear. There are two predominant hypotheses $[8,11]$. One suggests functional heme deficiency develops during the acute attack, in liver and possibly in neural tissues, and impairs critical cell processes dependent on hemoproteins such as energy production by the mitochondrial electron transport chain. Studies utilizing mice deficient in porphobilinogen deaminase, an experimental model of acute intermittent porphyria, underscore the importance of functional heme deficiency in nervous tissue in the development of motor neuropathy [16-18]. The second hypothesis suggests that heme precursors and their metabolites accumulate to toxic levels during the acute attack. ALA, in particular, is implicated because it is produced excessively in all the acute hepatic porphyrias and may have neurotoxic properties $[8,11]$. Excessive ALA production occurs in lead poisoning due to lead-mediated inhibition of ALA dehydratase, and also in hereditary infantile tyrosinemia (type I) in which the enzyme defect leads to endogenous production of the ALA dehydratase inhibitor, succinylacetone [19]. In both diseases, neuropsychiatric symptoms that resemble those of the acute attack occur $[8,11]$. While recent clinical studies underscore the potential importance of excessive hepatic production of heme precursors as the primary cause of the neurologic complications in the acute porphyric attack $[20,21]$, induced elevation of plasma ALA in a human volunteer, by itself, did not produce symptoms of porphyria [22]. Clearly, many details are unresolved $[8,11]$.

\section{DOES PORPHYRIA OFFER INSIGHT ON AD?}

We hypothesize that heme deficiency is important in $\mathrm{AD}$ pathogenesis and that $\mathrm{AD}$ may differ significantly in individuals possessing the genetic trait for an acute hepatic porphyria because there is the potential to develop more severe heme deficiency. Figure 1 schematically depicts this hypothesis.

AD-related factors may create an imbalance in neuronal heme supply and demand. In $\mathrm{AD}$, heme supply may be reduced. Aging is the greatest risk factor for development of $\mathrm{AD}$, and at least in rat brain, heme biosynthesis declines in normal aging [25]. Nutritional factors could be important. Pyridoxine deficiency in the aged could contribute to age-related decrease in heme biosynthesis because pyridoxal phosphate is a cofactor for ALAS [10]. Glycoxidation reactions are prominent in AD brain [26], and glycoxidation reactions might inactivate enzymes required for heme biosynthesis [27]. Moreover, heme biosynthesis requires mitochondrial integrity and mitochondrial damage is prominent in $\mathrm{AD}$ [28]. In $\mathrm{AD}$, heme demand may be increased. Mitochondrial damage would necessitate increased mitochondrial turnover and de novo synthesis of heme-containing proteins such as cytochromes. Moreover, mitochondrial damage may itself be caused by heme deficiency $[29,30]$ thus creating a vicious cycle further impairing heme biosynthesis. Glycoxidation reactions could promote degradation of heme proteins [31]. Heme degradation may be favored over heme biosynthesis in AD neurons because of chronically elevated HO-1 $[32,33]$. Factors unique to AD could also increase heme demand. Thus, amyloid- $\beta[\mathrm{A} \beta]$ binds heme, which may contribute to development of a functional heme deficiency [6] and affect $\mathrm{A} \beta$ toxicity by inhibiting $\mathrm{A} \beta$ aggregation $[34,35]$. We speculate that the reduced capacity to synthesize heme in individuals with porphyria could exacerbate such an imbalance in heme supply and demand.

In addition, the two proposed mechanisms of nervous system dysfunction in the acute porphyric attack, functional heme deficiency and toxic accumulation of ALA, have cellular effects that could be important in $\mathrm{AD}$ pathogenesis. Inhibition of heme biosynthesis produced senescence-associated changes in gene expression in cultured mouse cortical neurons [36] and was proapoptotic in NGF-induced PC12 cells [37]. Increased oxidative stress, which is one of the earliest observed events in $\mathrm{AD}$ pathogenesis [38], and heme deficiency may help explain several pathophysiological features of $\mathrm{AD}$ including mitochondrial abnormalities and impaired energy metabolism, cell cycling and cell signaling abnormalities, neuritic pathology, and abnormal expression of iron regulatory protein 2 (IRP2) [5]. ALA is a source of 


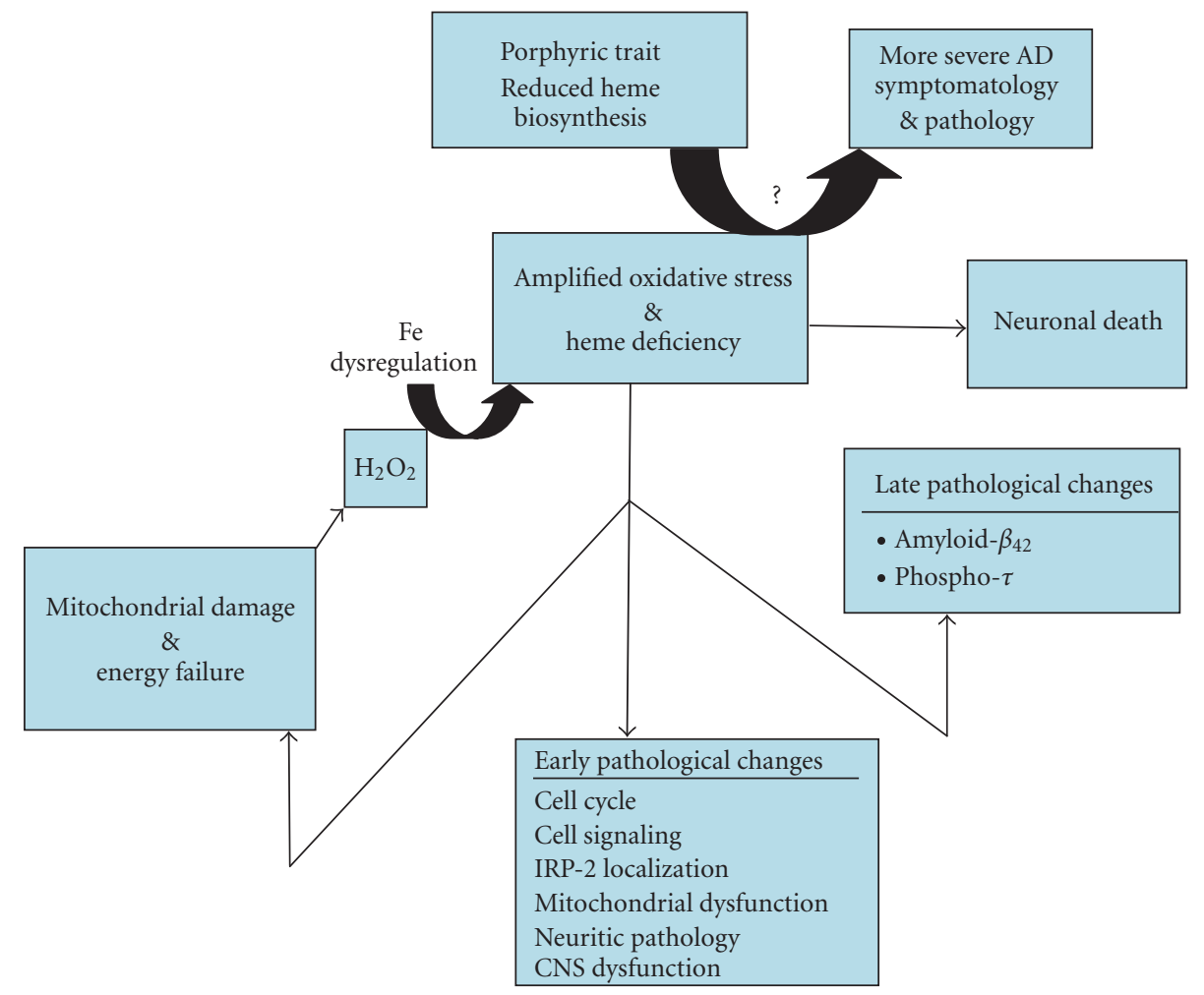

FIGURE 1: AD and porphyria. Oxidative stress and free radical damage occur early in AD [23]. Disruption in iron homeostatic mechanisms contributes to oxidative damage in $\mathrm{AD}$ [24]. A consequence of oxidative stress predicted by the ferric cycle hypothesis is heme deficiency $[4,5]$. Moreover, AD-related factors such as accumulation of amyloid- $\beta$ may limit heme bioavailability [6]. We hypothesize that reduced capacity for cells to synthesize heme, in individuals with the genetic trait for acute hepatic porphyria, contributes to development of heme deficiency (and possibly oxidative stress). AD-related pathological change and neuropsychiatric and behavioral symptoms associated with $\mathrm{AD}$ may be more severe in these individuals.

oxygen free radicals in the presence of heavy metals such as iron [39]. The product of iron-catalyzed oxidation of ALA, 4, 5-dioxovaleric acid, is an effective alkylating agent of guanine moieties in DNA in vitro $[40,41]$, and ALA-induced mitochondrial and nuclear DNA damage has been shown in several cell lines including PC12 cells [42]. Moreover, ALA may disrupt normal iron sequestration by ferritin. It released iron from ferritin in vitro $[43,44]$ and caused oxidative damage to the ferritin molecule [45]. As in the toxic mechanism proposed for homocysteine in AD pathogenesis [4, 5], ALA may make available a catalytic metal that can promote oxidative stress.

\section{DOES PORPHYRIA INCREASE THE RISK OF AD?}

Clinically overt acute hepatic porphyria (predominantly acute intermittent porphyria) is relatively rare with a prevalence of perhaps 5 per 100,000 [12]. However, the prevalence of the genetic trait for acute porphyria is far greater because perhaps $90 \%$ of affected individuals are clinically latent $[7,12]$. In a Finnish population the estimated prevalence of porphobilinogen deaminase deficiency, the biochemical defect in acute intermittent porphyria, was 1 per 500 [46]. Using gene analysis to supplement enzymatic analysis, the estimated prevalence of porphobilinogen deaminase deficiency in a French population was 1 per 1675 [47]. Consistent with the possibility that deficiency in heme biosynthesis could increase susceptibility for AD is the intriguing observation that the chromosomal location of genes encoding enzymes in the heme biosynthesis pathway correlate with genetic loci linked to sporadic, late-onset Alzheimer's disease (maximum lod score $\geqslant 1$ ) [48] (Table 1). However, the significance of this observation is unclear. In cases such as deficiency in porphobilinogen deaminase, heme deficiency alone may be insufficient to cause $\mathrm{AD}$ but could contribute to disease progression when superimposed on other disease processes. However, effects may be indirect and not related to heme levels. For example, the proximity of the ALA dehydratase gene to an AD-related locus is noted in Table 1. ALA dehydratase-porphyria is an extremely rare form of acute hepatic porphyria. Moreover, ALA dehydratase activity is far in excess of the activities of other enzymes in the heme biosynthetic pathway and for that reason > 95\% loss of activity is needed before clinical symptoms of porphyria develop [12]. However, ALA dehydratase is also a high $\mathrm{K}_{\mathrm{m}}$ enzyme. Under AD-associated conditions, toxic levels of ALA may possibly accumulate and contribute to $\mathrm{AD}$ pathogenesis. While interesting, any relationship between heme deficiency 
TABLE 1: Chromosomal locations of genes encoding enzymes of the heme biosynthesis pathway and genes linked to development of lateonset Alzheimer's disease.

\begin{tabular}{l|cc}
\hline Heme biosynthetic enzymes & Location $^{1}$ & $\begin{array}{c}\text { Closest } \\
\text { AD-related loci }\end{array}$ \\
\hline $\begin{array}{l}\text { ALAS-1 (EC 2.3.1.37) } \\
\text { ALA-dehydratase } \\
(\text { EC 4.2.1.24) }\end{array}$ & $3 \mathrm{p} 21$ & $3 \mathrm{p} 14,3 \mathrm{p} 26$ \\
$\begin{array}{l}\text { Porphobilinogen } \\
\text { deaminase (EC 4.3.1.8) }\end{array}$ & $9 \mathrm{q} 34$ & $9 \mathrm{q} 34$ \\
$\begin{array}{l}\text { Uroporphyrinogen } \\
\text { III synthase (EC 4.2.1.75) }\end{array}$ & $11 \mathrm{q} 23.3$ & $11 \mathrm{q} 25$ \\
$\begin{array}{l}\text { Uroporphyrinogen } \\
\text { decarboxylase (EC 4.1.1.37) }\end{array}$ & $1 \mathrm{p} 25.3$ & $10 \mathrm{q} 21-10 \mathrm{q} 25$ \\
$\begin{array}{l}\text { Coproporphyrinogen } \\
\text { III oxidase (EC 1.3.3.3) }\end{array}$ & $3 \mathrm{q} 12$ & $1 \mathrm{p} 31-1 \mathrm{p} 36$ \\
$\begin{array}{l}\text { Protoporphyrinogen } \\
\text { oxidase (EC 1.3.3.4) }\end{array}$ & $1 \mathrm{q} 22$ & $3 \mathrm{q} 28$ \\
$\begin{array}{l}\text { Ferrochelatase } \\
(\text { EC 4.99.1.1) }\end{array}$ & $18 \mathrm{q} 21.3$ & $1 \mathrm{q} 23,1 \mathrm{q} 24$ \\
\hline
\end{tabular}

${ }^{1}$ from Meissner et al [10].

${ }^{2}$ From Table 1 by Kamboh in [48].

${ }^{3}$ A deficiency is associated with a specific form of acute hepatic porphyria.

and $\mathrm{AD}$ is speculative. If the genetic trait for one of the acute hepatic porphyrias is a risk factor for $\mathrm{AD}$, why has this relationship gone unnoticed? The answer simply may be that the majority of individuals with the biochemical defects of acute porphyria are clinically latent, and that many genetic and environmental factors likely contribute to the development of sporadic, late-onset $\mathrm{AD}$.

\section{CONCLUSIONS}

AD may differ significantly in individuals who have the genetic trait for acute hepatic porphyria because there is the potential to develop more severe neuronal heme deficiency and possibly accumulate ALA and other heme precursors. Epidemiological data confirming a link between $\mathrm{AD}$ and porphyria would be an important test of the hypothesis. AD progression (from disease-free state, to mild cognitive impairment, to $\mathrm{AD}$ ) in individuals with a genetic trait for acute hepatic porphyria could be compared with $\mathrm{AD}$ progression in an unaffected cohort. Testing for the presence of a genetic trait for acute porphyria in individuals diagnosed with mild cognitive impairment or early $\mathrm{AD}$ might identify a unique subset of AD patients. Management decisions may need to be adjusted in such individuals to avoid potential sensitivity to common medications and novel therapeutic agents which, if porphyrinogenic, could exacerbate porphyria and possibly AD symptoms. Approaches such as these could yield significant new information on $\mathrm{AD}$ pathogenesis and treatment.

\section{ACKNOWLEDGMENTS}

The Medical Research Service of the Department of Veterans Affairs (BED), the National Institutes of Health, and the Alzheimer's Association (XZ, GP, MAS) supported this study. None of the sponsors, however, had any direct involvement with this work. The authors acknowledge Dr Dominick J. Balestra, Professor George H. Elder, Dr Frank R. Sharp, Dr Glenn S. Gerhard, and Dr Robert N. Nishimura for their helpful comments during preparation of the manuscript, and Dr Peter R. Sinclair for many informative discussions and invaluable assistance in preparation of the final text.

\section{REFERENCES}

[1] Smith MA. Alzheimer disease. International Review of Neurobiology. 1998;42:1-54.

[2] Scheff SW, Price DA. Synaptic pathology in Alzheimer's disease: a review of ultrastructural studies. Neurobiology of Aging. 2003;24(8):1029-1046.

[3] Schneider LS, Dagerman KS. Psychosis of Alzheimer's disease: clinical characteristics and history. Journal of Psychiatric Research. 2004;38(1):105-111.

[4] Dwyer BE, Raina AK, Perry G, Smith MA. Homocysteine and Alzheimer's disease: a modifiable risk? Free Radical Biology and Medicine. 2004;36(11):1471-1475.

[5] Dwyer BE, Takeda A, Zhu X, Perry G, Smith MA. Ferric cycle activity and Alzheimer disease. Current Neurovascular Research. 2005;2(3):261-267.

[6] Atamna H, Frey WH II. A role for heme in Alzheimer's disease: heme binds amyloid $\beta$ and has altered metabolism. Proceedings of the National Academy of Sciences of the United States of America. 2004;101(30):11153-11158.

[7] Elder GH, Hift RJ, Meissner PN. The acute porphyrias. The Lancet. 1997;349(9065):1613-1617.

[8] Meyer UA, Schuurmans MM, Lindberg RLP. Acute porphyrias: pathogenesis of neurological manifestations. Seminars in Liver Disease. 1998;18(1):43-52.

[9] Bonkovsky HL, Barnard GF. The porphyrias. Current Treatment Options in Gastroenterology. 2000;3(6):487-500.

[10] Meissner PN, Hift RJ, Kirsch RE. The porphyrias. In: Arias IM, Boyer JL, Chisari FV, Fausto N, Schacter D, Shafritz DA, eds. The Liver: Biology and Pathobiology. 4th ed. Philadelphia, Pa: Lippincott Williams and Wilkins; 2001:311-329.

[11] Albers JW, Fink JK. Porphyric neuropathy. Muscle and Nerve. 2004;30(4):410-422.

[12] Anderson KE, Bloomer JR, Bonkovsky HL, et al. Recommendations for the diagnosis and treatment of the acute porphyrias. Annals of Internal Medicine. 2005;142(6):439-450.

[13] Badminton MN, Elder GH. Molecular mechanisms of dominant expression in porphyria. Journal of Inherited Metabolic Disease. 2005;28(3):277-286.

[14] Handschin C, Lin J, Rhee J, et al. Nutritional regulation of hepatic heme biosynthesis and porphyria through PGC- $1 \alpha$. Cell. 2005;122(4):505-515.

[15] Li D. PGC-1 $\alpha$ : looking behind the sweet treat for porphyria. Cell. 2005;122(4):487-489.

[16] Lindberg RLP, Martini R, Baumgartner M, et al. Motor neuropathy in porphobilinogen deaminase-deficient mice imitates the peripheral neuropathy of human acute porphyria. Journal of Clinical Investigation. 1999;103(8):1127-1134. 
[17] Lindberg RLP, Porcher C, Grandchamp B, et al. Porphobilinogen deaminase deficiency in mice causes a neuropathy resembling that of human hepatic porphyria. Nature Genetics. 1996;12(2):195-199.

[18] Johansson A, Möller C, Fogh J, Harper P. Biochemical characterization of porphobilinogen deaminase-deficient mice during phenobarbital induction of heme synthesis and the effect of enzyme replacement. Molecular Medicine. 2003;9(912):193-199.

[19] Wyss PA, Boynton S, Chu J, Roth KS. Tissue distribution of succinylacetone in the rat in vivo: a possible basis for neurotoxicity in hereditary infantile tyrosinemia. Biochimica et Biophysica Acta. 1993;1182(3):323-328.

[20] Soonawalla ZF, Orug T, Badminton MN, et al. Liver transplantation as a cure for acute intermittent porphyria. The Lancet. 2004;363(9410):705-706.

[21] Solis C, Martinez-Bermejo A, Naidich TP, et al. Acute intermittent porphyria: studies of the severe homozygous dominant disease provides insights into the neurologic attacks in acute porphyrias. Archives of Neurology. 2004;61(11):17641770.

[22] Mustajoki P, Timonen K, Gorchein A, Seppalainen AM, Matikainen E, Tenhunen R. Sustained high plasma 5aminolaevulinic acid concentration in a volunteer: no porphyric symptoms. European Journal of Clinical Investigation. 1992;22(6):407-411.

[23] Zhu X, Raina AK, Perry G, Smith MA. Alzheimer's disease: the two-hit hypothesis. Lancet Neurology. 2004;3(4):219-226.

[24] Zecca L, Youdim MBH, Riederer P, Connor JR, Crichton RR. Iron, brain ageing and neurodegenerative disorders. Nature Reviews. Neuroscience. 2004;5(11):863-873.

[25] Paterniti JR Jr, Lin CIP, Beattie DS. $\delta$-Aminolevulinic acid synthetase: regulation of activity in various tissues of the aging rat. Archives of Biochemistry and Biophysics. 1978;191(2):792-797.

[26] Castellani RJ, Harris PLR, Sayre LM, et al. Active glycation in neurofibrillary pathology of Alzheimer disease: $\mathrm{N}^{\varepsilon}$ (carboxymethyl) lysine and hexitol-lysine. Free Radical Biology and Medicine. 2001;31(2):175-180.

[27] Caballero F, Gerez E, Batlle A, Vazquez E. Preventive aspirin treatment of streptozotocin induced diabetes: blockage of oxidative status and revertion of heme enzymes inhibition. Chemico-Biological Interactions. 2000;126(3):215-225.

[28] Castellani R, Hirai K, Aliev G, et al. Role of mitochondrial dysfunction in Alzheimer's disease. Journal of Neuroscience Research. 2002;70(3):357-360.

[29] Atamna H, Killilea DW, Killilea AN, Ames BN. Heme deficiency may be a factor in the mitochondrial and neuronal decay of aging. Proceedings of the National Academy of Sciences of the United States of America. 2002;99(23):14807-14812.

[30] Atamna H, Liu J, Ames BN. Heme deficiency selectively interrupts assembly of mitochondrial complex IV in human fibroblasts: relevance to aging. Journal of Biological Chemistry. 2001;276(51):48410-48416.

[31] Cussimanio BL, Booth AA, Todd P, Hudson BG, Khalifah RG. Unusual susceptibility of heme proteins to damage by glucose during non-enzymatic glycation. Biophysical Chemistry. 2003;105(2-3):743-755.

[32] Smith MA, Kutty RK, Richey PL, et al. Heme oxygenase-1 is associated with the neurofibrillary pathology of Alzheimer's disease. American Journal of Pathology. 1994;145(1):42-47.
[33] Schipper HM, Cisse S, Stopa EG. Expression of heme oxygenase- 1 in the senescent and Alzheimer-diseased brain. Annals of Neurology. 1995;37(6):758-768.

[34] Howlett D, Cutler P, Heales S, Camilleri P. Hemin and related porphyrins inhibit $\beta$-amyloid aggregation. FEBS Letters. 1997; 417(2):249-251.

[35] Ahn BW, Song DU, Jung YD, et al. Detection of $\beta$-amyloid peptide aggregation using DNA electrophoresis. Analytical Biochemistry. 2000;284(2):401-405.

[36] Chernova T, Nicotera P, Smith AG. Heme deficiency is associated with senescence and causes suppression of N-methylD-aspartate receptor subunits expression in primary cortical neurons. Molecular Pharmacology. 2006;69(3):697-705.

[37] Sengupta A, Hon T, Zhang L. Heme deficiency suppresses the expression of key neuronal genes and causes neuronal cell death. Molecular Brain Research. 2005;137(1-2):23-30.

[38] Perry G, Nunomura A, Cash AD, et al. Reactive oxygen: its sources and significance in Alzheimer disease. Journal of Neural Transmission, Supplement. 2002;(62):69-75.

[39] Monteiro HP, Abdalla DSP, Faljoni-Alario A, Bechara EJH. Generation of active oxygen species during coupled auto oxidation of oxyhemoglobin and $\delta$-aminolevulinic acid. Biochimica et Biophysica Acta. 1986;881(1):100-106.

[40] Douki T, Onuki J, Medeiros MHG, Bechara EJH, Cadet J, Di Mascio P. DNA alkylation by 4,5-dioxovaleric acid, the final oxidation product of 5-aminolevulinic acid. Chemical Research in Toxicology. 1998;11(2):150-157.

[41] Di Mascio P, Teixeira PC, Onuki J, et al. DNA damage by 5aminolevulinic and 4,5-dioxovaleric acids in the presence of ferritin. Archives of Biochemistry and Biophysics. 2000;373(2): 368-374.

[42] Onuki J, Chen Y, Teixeira PC, et al. Mitochondrial and nuclear DNA damage induced by 5 -aminolevulinic acid. Archives of Biochemistry and Biophysics. 2004;432(2):178-187.

[43] Oteiza PI, Kleinman CG, Demasi M, Bechara EJH. 5-Aminolevulinic acid induces iron release from ferritin. Archives of Biochemistry and Biophysics. 1995;316(1):607-611.

[44] Rocha MEM, Ferreira AMDC, Bechara EJH. Roles of phosphate and an enoyl radical in ferritin iron mobilization by 5aminolevulinic acid. Free Radical Biology and Medicine. 2000; 29(12):1272-1279.

[45] Rocha MEM, Dutra F, Bandy B, et al. Oxidative damage to ferritin by 5 -aminolevulinic acid. Archives of Biochemistry and Biophysics. 2003;409(2):349-356.

[46] Mustajoki P, Kauppinen R, Lannfelt L, Lilius L, Koistinen J. Frequency of low erythrocyte porphobilinogen deaminase activity in Finland. Journal of Internal Medicine. 1992; 231(4):389-395.

[47] Nordmann Y, Puy H, Da Silva V, et al. Acute intermittent porphyria: prevalence of mutations in the porphobilinogen deaminase gene in blood donors in France. Journal of Internal Medicine. 1997;242(3):213-217.

[48] Kamboh MI. Molecular genetics of late-onset Alzheimer's disease. Annals of Human Genetics. 2004;68(4):381-404. 


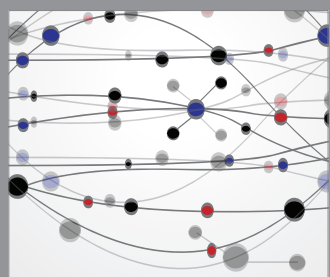

The Scientific World Journal
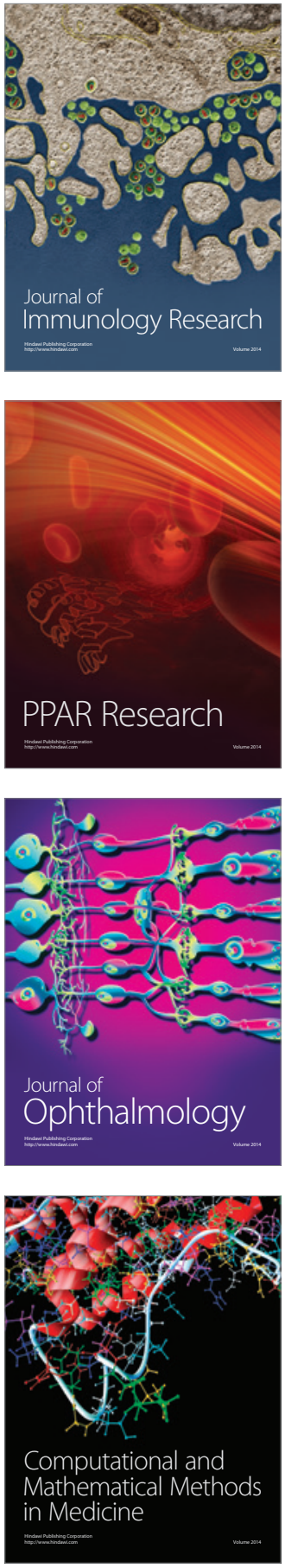

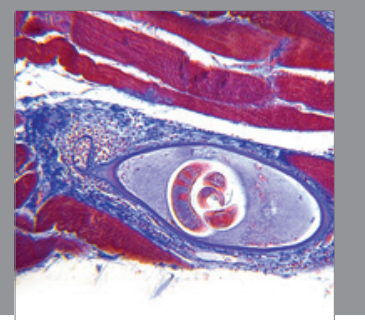

Gastroenterology

Research and Practice
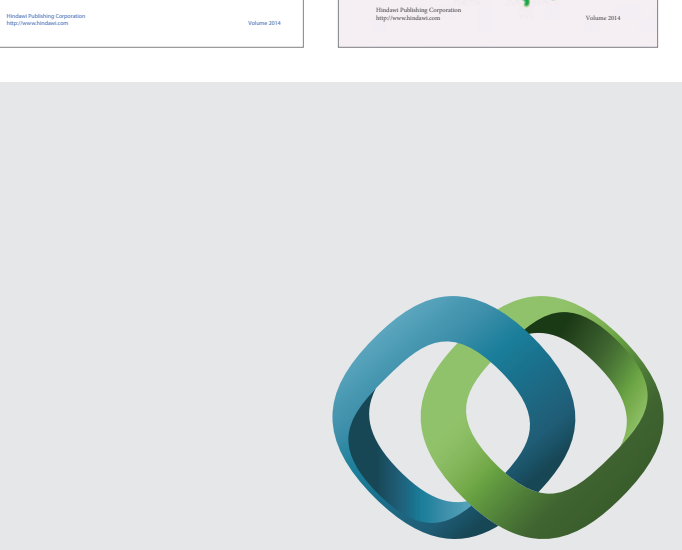

\section{Hindawi}

Submit your manuscripts at

http://www.hindawi.com
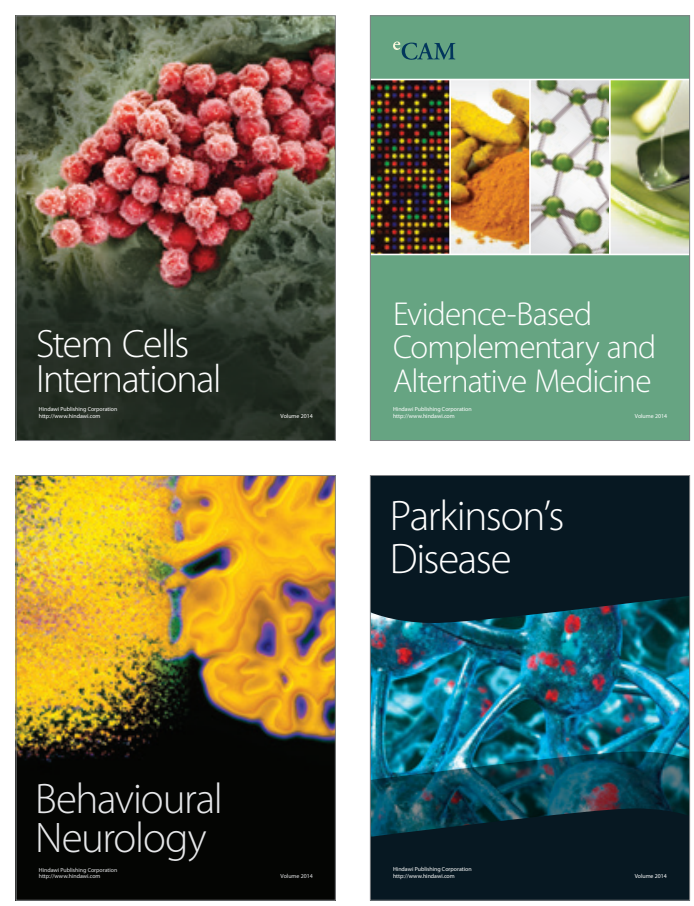

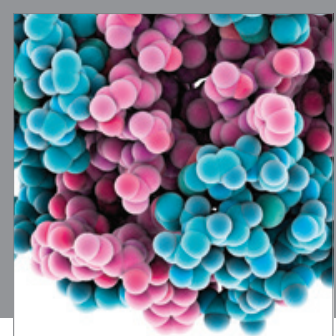

Journal of
Diabetes Research

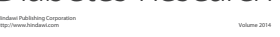

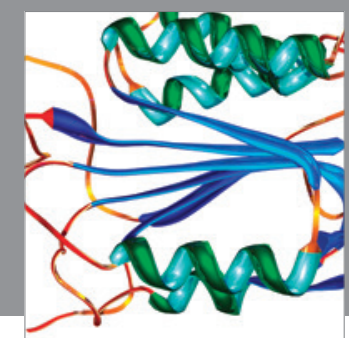

Disease Markers
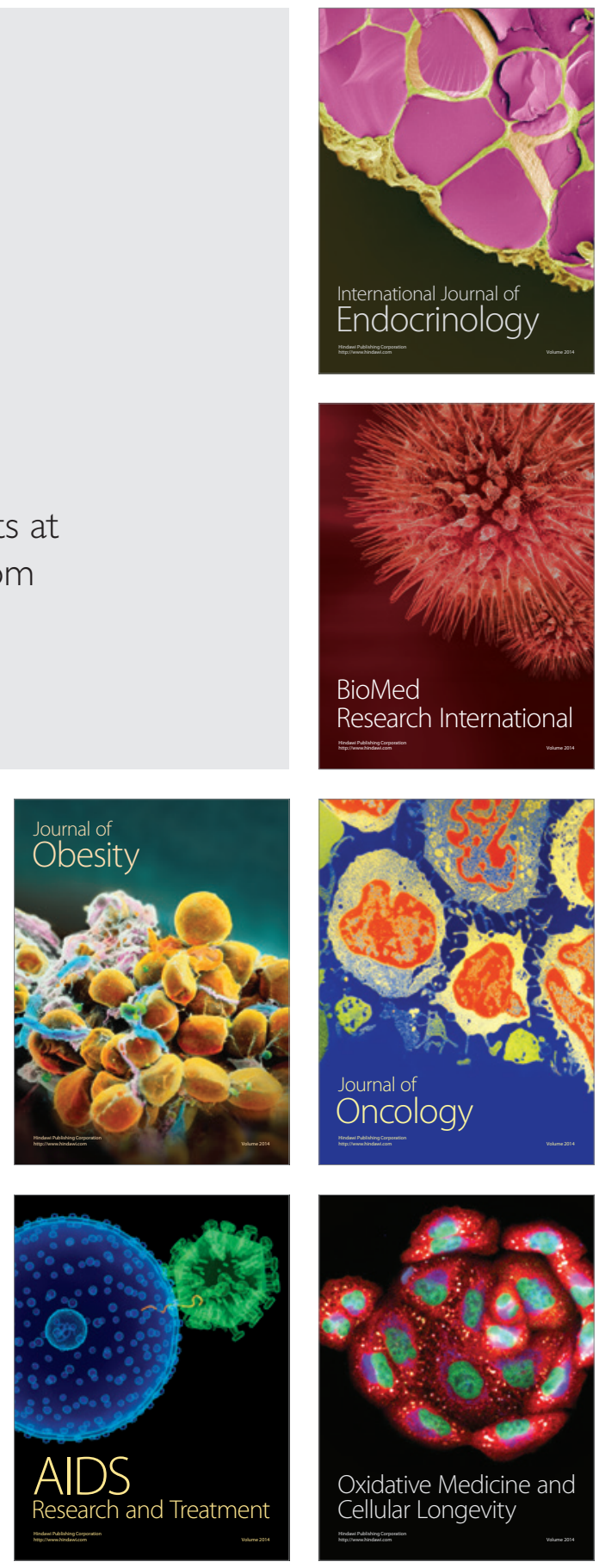